\title{
THE APRIL MEETING IN MADISON
}

The six hundred seventy-fourth meeting of the American Mathematical Society was held at the Wisconsin Center of the University of Wisconsin, Madison, Wisconsin on Tuesday through Saturday, April 14-18, 1970, in conjunction with the 1970 spring meeting of the Association of Symbolic Logic. There were 487 registrants, including 421 members of the Society.

By invitation of the Committee to Select Hour Speakers for Western Sectional Meetings there were four one-hour addresses. Professor Jack E. McLaughlin of the University of Michigan spoke Friday morning on Finite groups generated by transvections. He was introduced by Professor Richard H. Bruck. Professor Kurt Mahler of the Ohio State University addressed the Society on Friday afternoon, with Professor Patrick X. Gallagher presiding. Professor Mahler's subject was Geometry of numbers of convex bodies. Professor Lee A. Rubel of the University of Illinois, who was introduced by Professor R. Creighton Buck, spoke Saturday morning. His talk was entitled Bounded convergence of analytic functions. Professor Morton L. Curtis of Rice University and the University of California, Berkeley, addressed the Society on Saturday afternoon. His topic was Finite-dimensional $H$-spaces; he was introduced by Dr. MaryEllen Rudin.

By invitation of the same committee there were three special sessions of selected twenty-minute papers. One of these, held Friday morning and afternoon, was arranged by Professor John H. Walter of the University of Illinois on the subject of Finite Simple Groups; Professor Walter presided during the morning and Professor Daniel Gorenstein during the afternoon. The speakers were Jonathan $\mathrm{L}$. Alperin, Michael J. Collins, George Glauberman, Daniel Gorenstein, Koichiro Harada, William M. Kantor, Takeshi Kondo, Michael E. O'Nan, Ernest E. Shult, W. Brian Stewart, Michio Suzuki, and John H. Walter. Another special session, held Saturday morning, was on the subject of Geometric Topology and was arranged by Professor James M. Kister of the University of Michigan and Cambridge University; Professor R. H. Bing presided at the actual session. The speakers were James W. Cannon, Jerome Dancis, Richard K. Lashof, Ewing L. Lusk, Richard T. Miller, and Laurence C. Siebenmann. The third special session, held Saturday morning and afternoon, was arranged by Professor John $\mathrm{H}$. Nohel of the University of Wisconsin on the subject of Qualitative Theory for Functional and Differential Equations. The speakers were Fred G. Brauer, 
Charles C. Conley, Neil H. Fenichel, Jacob J. Levin, Richard P. McGehee, Kenneth R. Meyer, Paul H. Rabinowitz, Joel W. Robbin, Aaron S. Strauss, and James A. Yorke; Professor Nohel presided throughout.

There were ten sessions of contributed ten-minute papers. These were chaired by Professors Steven Bauman, Simon Hellerstein, Kenneth Kunen, Lawrence S. Levy, Joseph M. Martin, J. Marshall Osborn, Walter Rudin, Isaac J. Schoenberg, Daniel F. Shea, and Wolfgang R. Wasow. Of the 66 ten-minute papers listed in the program of the meeting, 6 were presented by title; 7 late papers were added to the program, so that 67 ten-minute papers were actually presented.

With the support of the National Science Foundation there was a symposium on Representation Theory of Finite Groups and Related Topics on Tuesday, Wednesday, and Thursday. This topic was chosen by the Committee to Select Hour Speakers for Western Sectional Meetings. The Organizing Committee of the Symposium consisted of Irving Reiner (chairman), Richard Brauer, Charles W. Curtis, Walter Feit, and James A. Green. The speakers at the Symposium were Clark Benson, Richard Brauer, P. Nicholas Burgoyne, Edward T. Cline, Samuel B. Conlon, Charles W. Curtis, Everett C. Dade, Larry L. Dornhoff, Andreas W. M. Dress, Paul Fong, Patrick X. Gallagher, David M. Goldschmidt, James A. Green, Larry C. Grove, Donald G. Higman, I. Martin Isaacs, Noboru Ito, Heinz Jacobinski, Gerald J. Janusz, Robert W. Kilmoyer, Jr., Karl Kronstein, Tsit-Yuen Lam, John H. Lindsey II, Donald S. Passman, Irving Reiner, William F. Reynolds, Klaus W. Roggenkamp, Leonard L. Scott, Jr., Louis Solomon, Tonny A. Springer, Richard G. Swan, David B. Wales, Walter D. Wallis, Warren J. Wong, Hans J. Zassenhaus, and Janice R. Zemanek. 